\title{
Induction of Phytohormones and Differential Gene Expression in Citrus Flowers Infected by the Fungus Colletotrichum acutatum
}

\author{
Katherine A. Lahey, ${ }^{1}$ Rongcai Yuan, ${ }^{1}$ Jacqueline K. Burns, ${ }^{1,2}$ Peter P. Ueng, ${ }^{3}$ L. W. Timmer, ${ }^{1,4}$ and Kuang- \\ Ren Chung ${ }^{1,4}$ \\ ${ }^{1}$ Citrus Research and Education Center, Institute of Food and Agricultural Sciences (IFAS), University of Florida, Lake \\ Alfred FL 33850, U.S.A.; ${ }^{2}$ Horticultural Sciences Department, IFAS, University of Florida, Gainesville 32611, U.S.A.; \\ ${ }^{3}$ Molecular Plant Pathology Lab., United States Department of Agriculture-Agricultural Research Service, BARC-West, \\ 10300 Baltimore Ave., Beltsville, MD 20705, U.S.A.; and ${ }^{4}$ Department of Plant Pathology, IFAS, University of Florida, \\ Gainesville 32611, U.S.A.
}

Submitted 7 May 2004. Accepted 17 August 2004.

Colletotrichum acutatum infects citrus petals and induces premature fruit drop and the formation of persistent calyces. The accumulation of hormones and other growth regulators, and differential gene expression in affected flowers and young fruit, was examined following fungal infection. Ethylene evolution increased threefold and indole-3-acetic acid (IAA) accumulation was as much as 140 times. Abscisic acid (ABA) levels showed no significant response. After infection, both trans- and cis-12-oxo-phytodienoic acid increased 8- to 10-fold. No significant difference of transjasmonic acid (JA) was observed in citrus flower petals or pistils. However, a fivefold increase of cis-JA was detected. The amount of salicylic acid (SA) was elevated twofold in affected petals, but not in pistils. Northern blot analyses revealed that the genes encoding ACC oxidase or ACC synthase, and 12-oxo-phytodienoic acid (12-oxo-PDA) reductase, were highly expressed in affected flowers. The genes encoding auxin-related proteins also were upregulated. Application of 2-(4-chlorophenoxy)-2-methyl-propionic acid (clofibrate; a putative auxin inhibitor), 2,3,5-triiodobenzolic acid (an auxin transport inhibitor), or SA after inoculation significantly decreased the accumulation of the gene transcripts of auxin-responsive, GH3-like protein and 12oxo-PDA reductase, but resulted in higher percentages of young fruit retention. The results indicate that imbalance of IAA, ethylene, and $\mathrm{JA}$ in $C$. acutatum-infected flowers may be involved in symptom development and young fruit drop.

Additional keywords: abscission, sweet orange.

Colletotrichum spp. cause three important diseases in citrus. Postbloom fruit drop (PFD) and key lime anthracnose (KLA) are caused by $C$. acutatum J. H. Simmonds, whereas postharvest anthracnose is caused by $C$. gloeosporioides (Penz.) Penz. $\&$ Sacc. Postharvest anthracnose on fruit is a relatively minor problem, but is enhanced by ethylene degreening (Brown 1992; Timmer et al. 1998). PFD causes serious yield losses of sweet orange and other citrus in the humid climate of Central and South America. PFD fungal isolates infect flower petals of

Corresponding author: K.-R. Chung; Telephone: (863) 956-1151 ext. 1369; Fax: (863) 956-4631; E-mail: krchung@crec.ifas.ufl.edu most citrus cultivars, resulting in blossom blight, young fruit drop, and induction of persistent calyces (Timmer et al. 1994). PFD isolates are only weakly pathogenic on Mexican lime. In contrast, KLA is a serious problem in humid areas, where it produces severe anthracnose of leaves, twigs, flowers, and shoots only on Mexican lime. Like PFD, KLA fungal isolates also can infect flowers of sweet orange, producing blossom blight symptoms, persistent calyces, and young fruit drop. In addition to differences in host specificity, KLA and PFD isolates also can be differentiated based on morphological differences (Agostini et al. 1992), variation in isozymes of cutinase, differences in ribosomal and mitochondrial DNA restriction fragment length polymorphisms, and chromosome sizes (Brown et al. 1996; Liyanage et al. 1992, 1993).

PFD isolates of $C$. acutatum infect only flower petals and produce acervuli on the affected petals four to five days under optimal conditions. The disease incidence caused by PFD isolates is highly dependent on rainfall and blooming. The fungus persists as appressoria, but forms quiescent infections on vegetative tissues in the absence of blooms. Unlike other Colletotrichum spp., C. acutatum PFD isolates do not attack citrus tissues during the quiescent stage. Appressoria germinate directly to produce hyphae and a few conidia that initiate infection on the flower petals. Subsequently, more conidia are produced in acervuli and are dispersed by rain splash from flower to flower (Timmer et al. 1994).

As with many fruit trees, citrus tends to set excessive numbers of flowers and fruit and undergoes natural drop of immature fruit to adjust fruit load. Less than $1 \%$ of citrus flowers eventually will set fruit. The mechanisms that cause physiological drop of young fruit are complex and highly variable among plant species. Natural young fruit drop likely is associated with various factors, including nutritional status of the plant, embryogenesis disturbance, adverse environmental conditions, nutrient competition, and hormone regulations (Bonghi et al. 2000; Gómez-Cadenas et al. 2000). Similar to fruit abscission, the processes of young fruit abscission may involve a series of programmed alterations in cell morphology and tissue digestion (Goren 1993). The processes are regulated by phytohormones such as ethylene and auxin that subsequently influence the production of cell wall-degrading enzymes such as $\beta$-1,4-endoglucanase and polygalacturonase (Bangerth 1997, 2000; Bonghi et al. 2000; Talon et al. 1997). The processes involved in natural drop and fun- 
gal-induced drop, however, might not be completely identical. Natural abscission of citrus young fruit usually occurs between the shoot and the peduncle, leaving no trace of the presence of flowers. Infection of citrus flower petals by $C$. acutatum also triggers postbloom fruit drop. Unlike natural young fruit drop, abscission of young fruit caused by $C$. $a c u$ tatum takes place at the abscission zone located between the calyces and the young fruit. The calyx (commonly called buttons) continues to enlarge after the young fruit abscises and remains attached to the peduncle. Leaves around the affected flowers are often smaller and distorted with swollen veins. These observations have led us to hypothesize that phytohormones are likely involved in the symptoms associated with infection by C. acutatum (Chung et al. 2002b; Li et al. 2003). In this present work, we report significant elevation in the amounts of phytohormones and growth regulators, including indole-3-acetic acid (IAA), ethylene, jasmonic acid (JA), 12oxo-phytodienoic acid (12-oxo-PDA), and salicylic acid (SA). The results confirm the hypothesis that phytohormones are involved in abscission of young fruit and persistence of calyces associated with PFD.

\section{RESULTS}

IAA accumulation and gene expression

in response to $C$. acutatum infection.

As a first step toward understanding the role of phytohormones in the development of PFD caused by $C$. acutatum, levels of IAA were measured throughout the disease process. IAA accumulation was measured 3 days postinoculation in affected petals and increased markedly thereafter (Fig. 1A). Compared with the water control, the amount of IAA in affected petals was accumulated as much as 140-fold 5 days postinoculation. The accumulation of IAA in affected petals was correlated with symptom development. Brown necrotic lesions caused by $C$. acutatum usually appeared in petals within 4 to 5 days postinoculation. PFD isolates of $C$. $a c u$ tatum mainly infects flower petals; therefore, the level of IAA was much lower $(<0.1 \mathrm{nmoles} / \mathrm{g}$ of fresh tissue $)$ in pistils containing stigma, style, and ovary (Fig. 1B). However, significant accumulation of IAA was measured in pistils 5 days postinoculation, suggesting that transport of IAA from the infected sites occurred.

Differential expression patterns of DNA clones encoding genes associated with IAA or IAA regulation (Table 1) also were examined. Compared with the water control, the gene encoding auxin-responsive GH3-like protein (Roux et al. 1998) was upregulated in C. acutatum-infected petals 5 days postinoculation (Fig. 1C). Expression of the genes encoding a putative auxin response factor-like protein and glutathione $\mathrm{S}$ transferase (likely involved in auxin binding and plant stresses) (Anderson and Davis 2004) was slightly but not significantly induced in response to $C$. acutatum. In contrast, the expression patterns of the genes encoding IAA amino acid hydrolase and a putative growth regulator protein (likely involved in auxininduced cell elongation) (Dupree 1996) remained unaltered (Fig. 1C). Taken together, the results indicated that infection of C. acutatum triggers IAA accumulation and subsequent expression of genes associated with IAA.
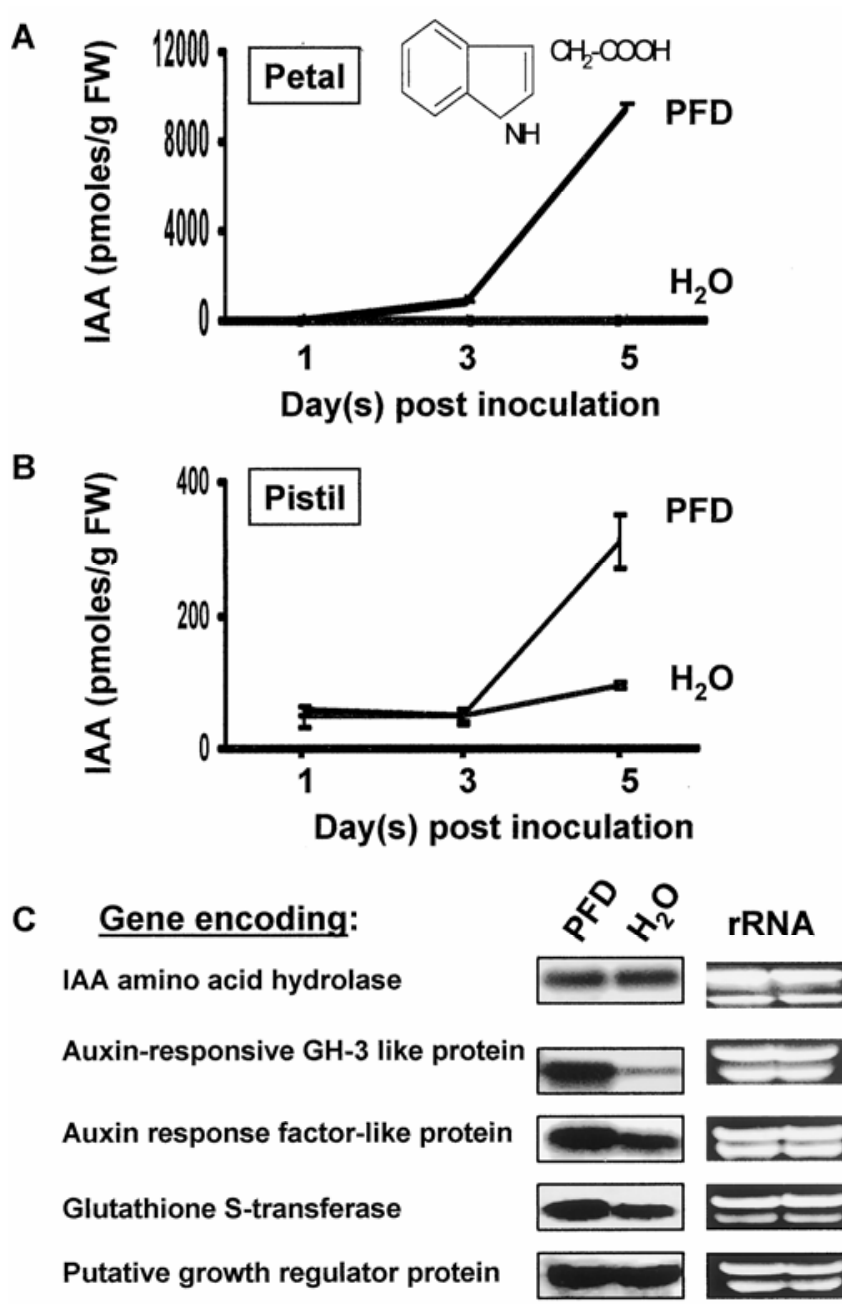

Fig. 1. Quantitative determination of indole-3-acetic acid (IAA) in calamondin (Citrus madurensis Lour) flower $\mathbf{A}$, petals and $\mathbf{B}$, pistils containing stigma, style, and ovary after Colletotrichum acutatum infection (postbloom fruit drop; PFD) or mock inoculation with water $\left(\mathrm{H}_{2} \mathrm{O}\right)$. IAA levels were determined using a monoclonal antibody. The data shown are the means and standard errors of three different experiments with five replicates. C, Northern-blot analysis of auxin-related gene expression during $C$. acutatum infection in calamondin flowers (left). Gels were stained with ethidium bromide to ensure equal loading of the RNA samples (right).

Table 1. DNA clones used to determine the expression profiles in citrus flowers following infection by Colletotrichum acutatum

\begin{tabular}{|c|c|c|c|c|}
\hline $\begin{array}{l}\text { Clone } \\
\text { no. }\end{array}$ & $\begin{array}{l}\text { Size } \\
\text { (bp) }\end{array}$ & Putative identity & Putative function & References \\
\hline 6 & 711 & Lactolylglutathione lyase & Detoxification of xenobiotics (likely induced by ABA) & Romo et al. 2001 \\
\hline 32 & 762 & Putative growth regulator protein & Likely involved in auxin-induced cell elongation, defense & Dupree 1996 \\
\hline 62 & 377 & Indole-3-acetic acid (IAA) amino acid hydrolase & Free IAA from conjugated form & Bartel and Fink 1995 \\
\hline 64 & 380 & ACC oxidase & Ethylene biosynthesis & Kaneta et al. 1997 \\
\hline 102 & 264 & Auxin-responsive GH3-like protein & Unknown & Roux et al. 1998 \\
\hline 159 & 510 & 12-oxophytodienoate reductase & Jasmonic acid biosynthesis, defense & Sanders et al. 2000 \\
\hline $6 \mathrm{P} 12$ & 433 & Glutathione S-transferase & Likely involved in auxin binding, defense & Anderson and Davis 2004 \\
\hline 24LB-16 & 416 & Auxin response factor-like protein & Induced by auxin & Nakamura et al. 1998 \\
\hline 0312 & 1,600 & ACC synthase & Ethylene biosynthesis & Wong et al. 1999 \\
\hline 0315 & 650 & 9-cis-epoxycarotenoid dioxygenase & ABA biosynthesis & Qin and Zeevaart 1999 \\
\hline
\end{tabular}


Ethylene accumulation and gene expression in response to $C$. acutatum infection.

Ethylene has been well known to play a regulatory role in abscission (Giovannoni 2001). The concentration of ethylene in healthy versus infected flowers was not significantly different up to 2 days postinoculation (Fig. 2A). Ethylene evolution steadily increased and reached a peak 5 days postinoculation. At this time, affected petals had begun to desiccate.

Differential expression of the genes encoding ACC oxidase and ACC synthase, two key enzymes involved in ethylene biosynthesis, also was determined. Northern blot analysis revealed that the transcripts of both genes were highly upregulated five days after C. acutatum infection (Fig. 2B). These results indicate that expression of genes involved in ethylene biosynthesis and ethylene evolution increase as result of infection.

\section{Abscisic acid (ABA) accumulation and gene expression in response to $C$. acutatum infection.}

In contrast to IAA and ethylene, the levels of ABA were not significantly altered in affected petals or pistils (Fig. 3A and B). ABA concentration increased slightly in healthy citrus petals after mock inoculation, but decreased in pistils. The transcripts of the genes encoding lactolyglutathione lyase (a putative ABA-regulated enzyme) (Romo et al. 2001), and 9-cis-epoxycarotenoid dioxygenase (a key enzyme in ABA biosynthesis) (Qin and Zeevaart 1999) also were constitutively expressed (Fig. 3C), indicating that ABA does not significantly change in response to $C$. acutatum infection.

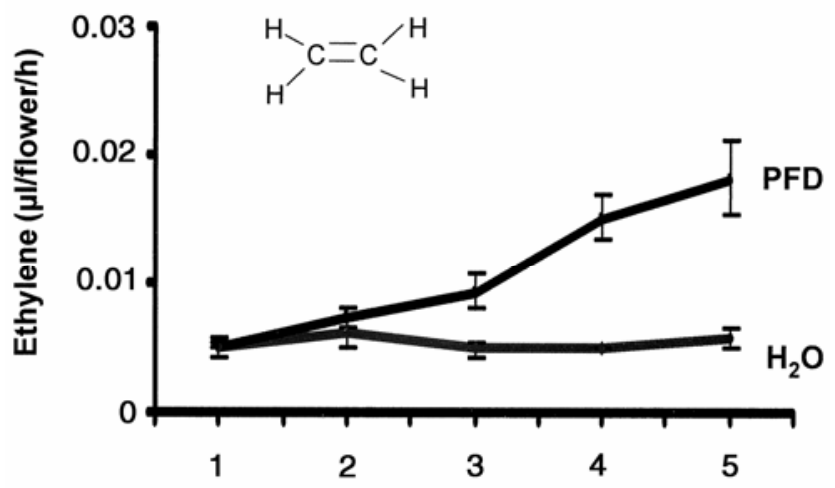

Day(s) post inoculation

B

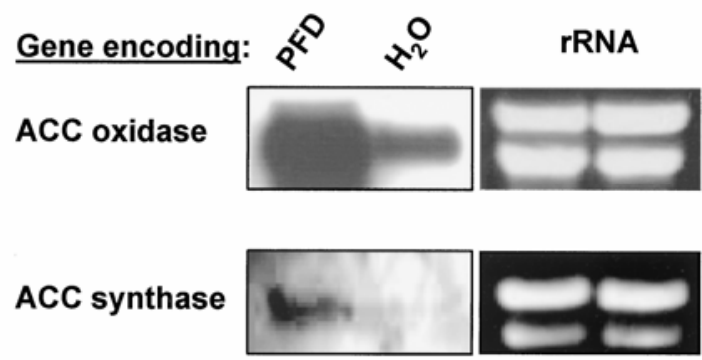

Fig. 2. A, Quantitative analysis of ethylene from calamondin flowers infected with Colletotrichum acutatum (postbloom fruit drop; PFD) or water mock inoculation $\left(\mathrm{H}_{2} \mathrm{O}\right)$. The data shown are the means and standard errors of three different experiments. B, Northern blot analysis of differential expression patterns of cDNA clones encoding ACC oxidase and ACC synthase during $C$. acutatum infection in calamondin flowers (left). Gels were stained with ethidium bromide to ensure equal loading of the RNA samples (right).
Accumulation of 12-oxo-PDA and JA, and gene expression in response to $C$. acutatum infection.

The compound 12-oxo-PDA is the JA biosynthetic precursor and also serves as an effective signal in plants (Stintzi et al. 2001). The levels of 12-oxo-PDA in citrus flowers were measured five days after inoculation. The results indicated that both trans and cis forms of 12-oxo-PDA were markedly induced in affected petals (Fig. 4A and B), whereas only slight but nonsignificant increase in 12-oxo-PDA was observed in pistils.

In contrast to 12-oxo-PDA, the trans form of JA was slightly downregulated in both petals and pistils following $C$. acutatum infection (Fig. 5A). However, the cis form of JA, as with 12oxo-PDA, was highly induced in petals but much less in pistils by $C$. acutatum (Fig. 5B). The transcript of the gene encoding 12-oxo-PDA reductase (likely involved in JA biosynthesis and plant defense) (Staswick et al. 2002) also was highly upregulated after fungal infection (Fig. 5C).

SA accumulation in response to $C$. acutatum infection.

The phenolic compound SA has been identified as a major signaling molecule in plant stress responses, including patho-

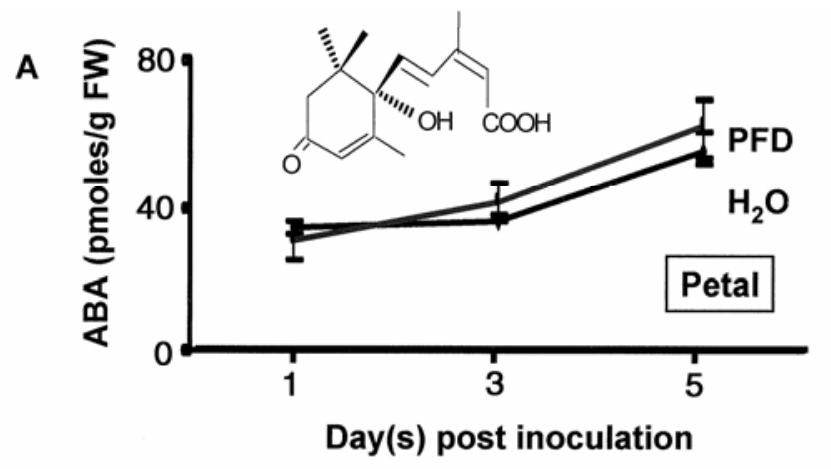

B

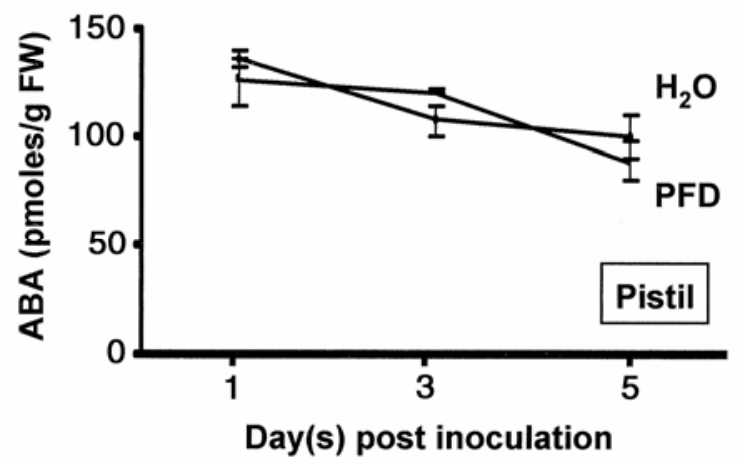

C
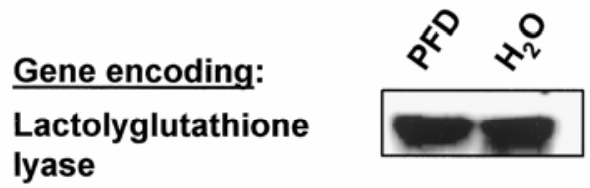

rRNA

\section{9-cis-epoxycarotenoid dioxygenase}
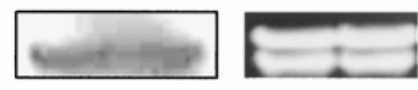

Fig. 3. Quantitative determination of abscisic acid (ABA) in calamondin flower A, petals and B, pistils, following Colletotrichum acutatum infection. ABA levels were determined in flowers infected with $C$. acutatum (postbloom fruit drop; PFD) or water control $\left(\mathrm{H}_{2} \mathrm{O}\right)$ using a monoclonal antibody. The data shown are the means and standard errors of three different experiments. C, RNA gel blot analysis of differential expression profiles of DNA clones encoding ABA-associated lactolyglutathione lyase and 9-cis epoxycarotenoid dioxygenase during $C$. acutatum infection in calamondin flowers (left). Gels were stained with ethidium bromide to ensure equal loading of the RNA samples (right). 
gen attack (Dong 1998). Therefore, the endogenous levels of SA were determined in citrus flowers infected with $C$. $a c u$ tatum. SA levels were increased approximately twofold in affected flower petals five days after inoculation (Fig. 6). The levels of SA were slightly less in pistils than in the water control.

\section{Effects of hormone inhibitors}

\section{on gene expression and young fruit retention.}

Pharmacological application of compounds with anti-IAA and JA activities were evaluated for their effects on gene expression and young fruit retention after fungal infection. Treating the affected petals with 2-(4-chlorophenoxy)-2-methylpropionic acid (clofibrate; a putative auxin inhibitor) (SosaMorales et al. 1997) three days after inoculation completely suppressed the transcripts of auxin-responsive GH3-like protein and 12-oxo-PDA reductase (Fig. 7). The compound 2,3,5triiodobenzolic acid (TIBA; an auxin transport inhibitor) (Tsurumi and Ohwaki 1978) at $100 \mu \mathrm{M}$ had little effect on the reduction of gene expression. However, the transcript of the gene encoding auxin-responsive GH3-like protein, but not 12oxo-PDA reductase, was reduced drastically by TIBA at high concentration $(1 \mathrm{mM})$. Application of SA (a potent JA inhibitor) after fungal infection also markedly decreased the transcripts of two gene markers (Fig. 7).

Compounds with hormone inhibitory effects were assessed for fruit retention in grapefruit and sweet orange to further determine the role of hormones in young fruit drop. Infection of cit-

A

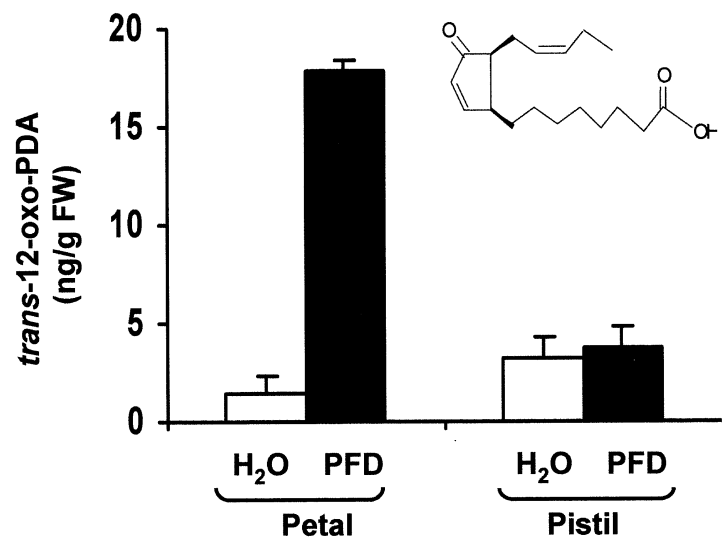

B

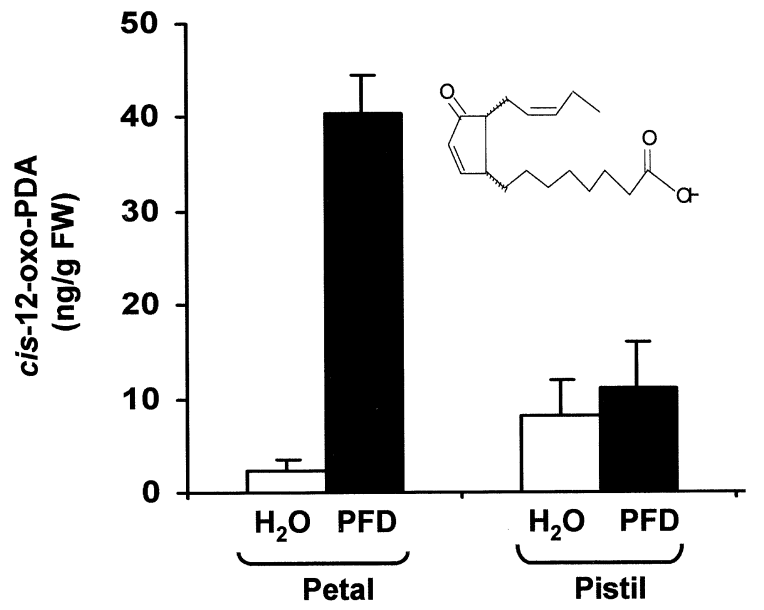

Fig. 4. Quantitative determination of 12-oxo-phytodienoic acid (12-oxoPDA) in calamondin flower petals and pistils 5 days postinoculation with Colletotrichum acutatum (postbloom fruit drop; PFD), and with water control $\left(\mathrm{H}_{2} \mathrm{O}\right)$. A, Accumulation of trans-12-oxo-PDA following inoculation. B, Accumulation of cis-12-oxo-PDA following inoculation. The data shown are the means and standard errors. rus flowers by $C$. acutatum resulted in severe fruit drop. For positive controls, application of a protective fungicide (Benlate) 1 day prior to fungal inoculation provided a higher percentage of fruit retention in sweet orange but not in grapefruit compared with that of the water controls. Application of the auxin transport inhibitor TIBA at concentrations of 1 and $100 \mu \mathrm{M}$ increased fruit retention in grapefruit and sweet orange (Table 2). Higher concentration of TIBA $(>1 \mathrm{mM})$, however, resulted in severe defoliation and twig damage. Application of clofibrate and SA also yielded a higher percentage of fruit retention in trees. Clofibrate at $100 \mu \mathrm{M}$ and $1 \mathrm{mM}$ caused a mild defoliation in sweet orange. SA caused phytotoxicity at concentrations of $10 \mathrm{mM}$ and higher (data not shown).

\section{DISCUSSION}

Hormones and many growth regulators are present in plants in very small amounts, yet act in a well-balanced, cooperative manner to regulate plant growth and development. Any change from normal levels of phytohormones such as those caused by infection with pathogens could significantly alter physiological processes and morphology, resulting in symptoms such as stunting, gall formation, epinasty, and abscission.

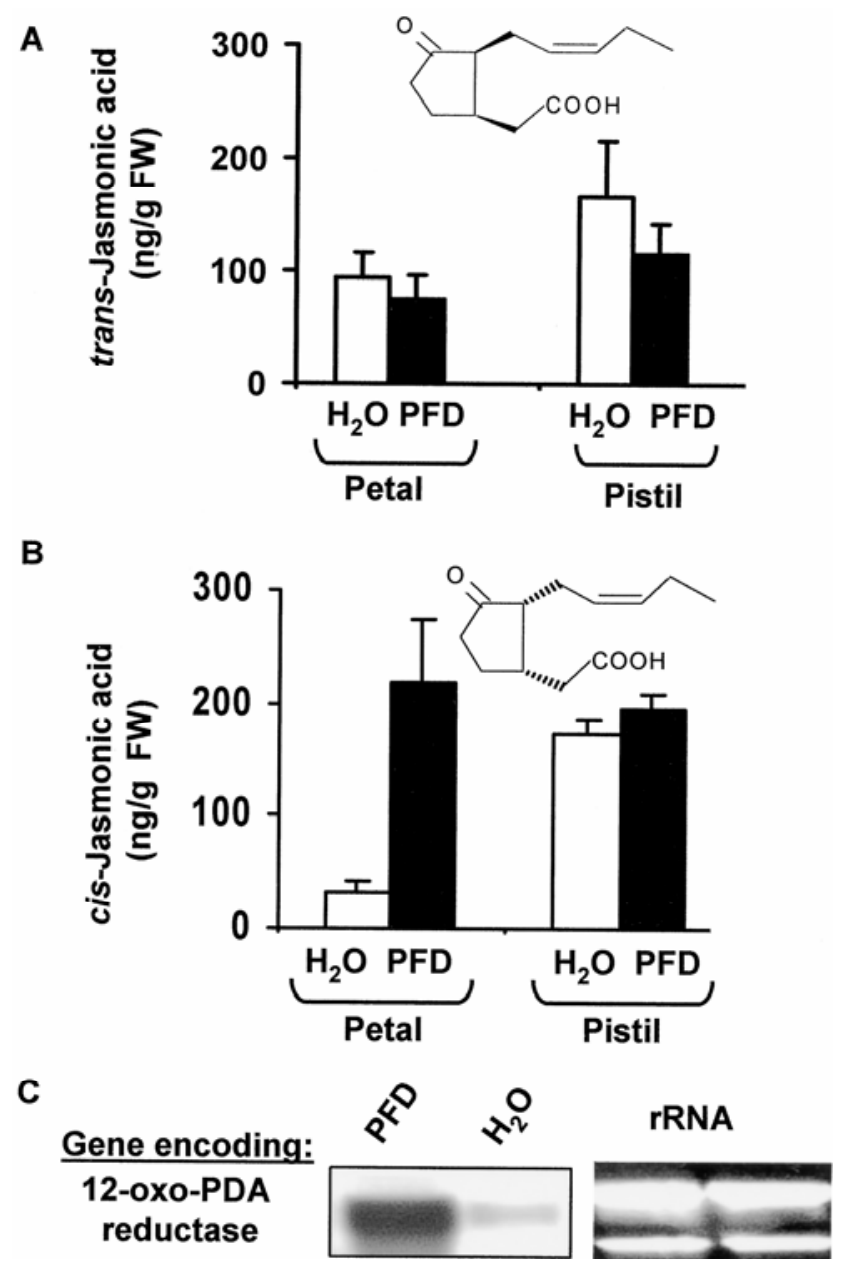

Fig. 5. Quantitative determination of jasmonic acid in calamondin flower petals and pistils 5 days postinoculation with Colletotrichum acutatum (postbloom fruit drop; PFD) and with water control $\left(\mathrm{H}_{2} \mathrm{O}\right)$. A, Accumulation of trans-jasmonic acid (JA) following infection. B, Accumulation of cis-JA following infection. The data shown are the means and standard errors. C, Northern blot analysis of differential expression patterns of a cDNA clone encoding 12-oxo-phytodienoic acid (12-oxo-PDA) reductase during $C$. acutatum infection of calamondin flowers (left). Gel was stained with ethidium bromide to ensure equal loading of the RNA samples (right). 
Among the growth regulators, auxins (mainly IAA) play a central role in regulation of plant growth and development, including cell elongation and differentiation, root initiation, tropisms (phototropic and gravitropic), and apical dominance. This study demonstrated a significant accumulation of IAA in citrus flower petals following $C$. acutatum infection. Higher amounts of IAA also were detected in pistils, where no fungal colonization occurs, indicative of IAA transport from the infection sites or transport of a "factor" from the infection sites that induces IAA formation. Genes with identities to auxin-responsive GH-3like protein (Roux et al. 1998), auxin-response factor-like protein (Nakamura et al. 1998), and auxin-responsive glutathione Stransferase (Anderson and Davis 2004) also were upregulated after $C$. acutatum infection. Furthermore, the increase of IAA levels in response to $C$. acutatum infection may suggest that

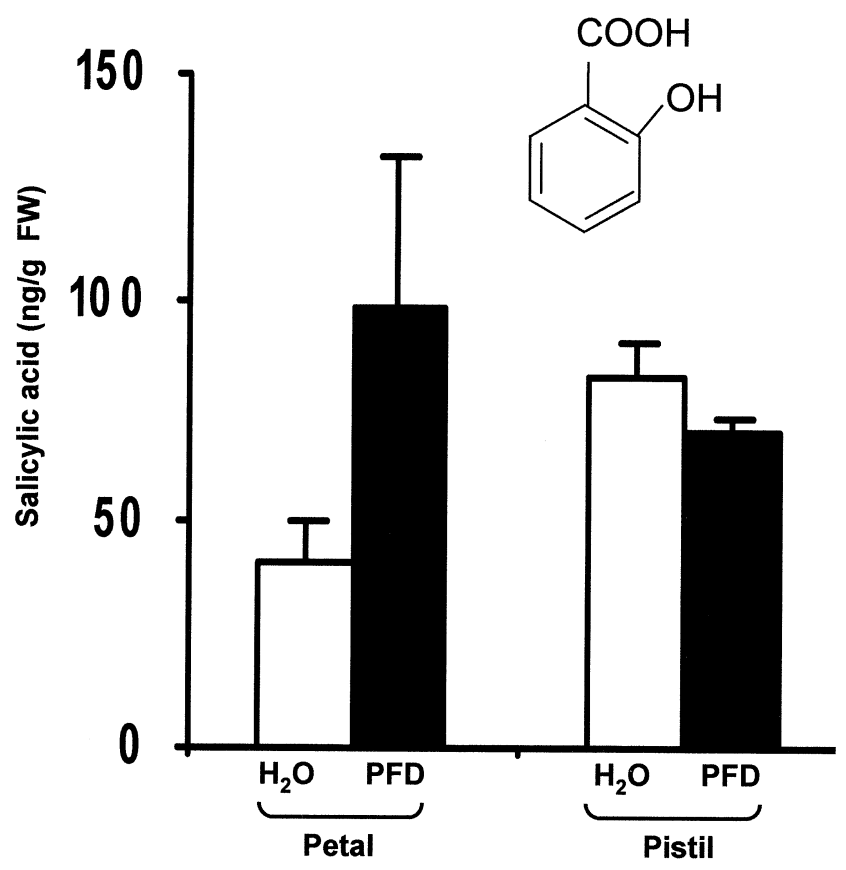

Fig. 6. Quantitative determination of salicylic acid in calamondin flower petals and pistils five days after inoculation with Colletotrichum acutatum (postbloom fruit drop; PFD), and with water control $\left(\mathrm{H}_{2} \mathrm{O}\right)$. The data shown are the means and standard errors.
IAA is associated with the plant defense response. Increased IAA levels in the affected flowers can result from de novo biosynthesis by the host plant or pathogen. However, C. acutatum isolates were found to produce IAA and other indole compounds in culture (Chung et al. 2003b), suggesting that the increased IAA in citrus flower petals following $C$. acutatum infection could originate in part from the causal fungus. The timing and magnitude of IAA accumulation was associated with the development of infection-dependent petal lesions, indicating that increased IAA is associated with symptom development.

IAA at physiologically high levels can trigger young fruit drop (Bangerth 2000; Goren 1993). High levels of IAA also may contribute to other symptom development, such as formation of enlarged calyces and subtending leaves. Application of clofibrate (Sosa-Morales et al. 1997), TIBA, or SA 3 days postinoculation significantly decreased the accumulation of the gene transcript of auxin-responsive GH3-like protein. Application of these compounds resulted in higher percentages of young fruit retention, indicating that IAA may play an important role in fruit drop caused by $C$. acutatum.

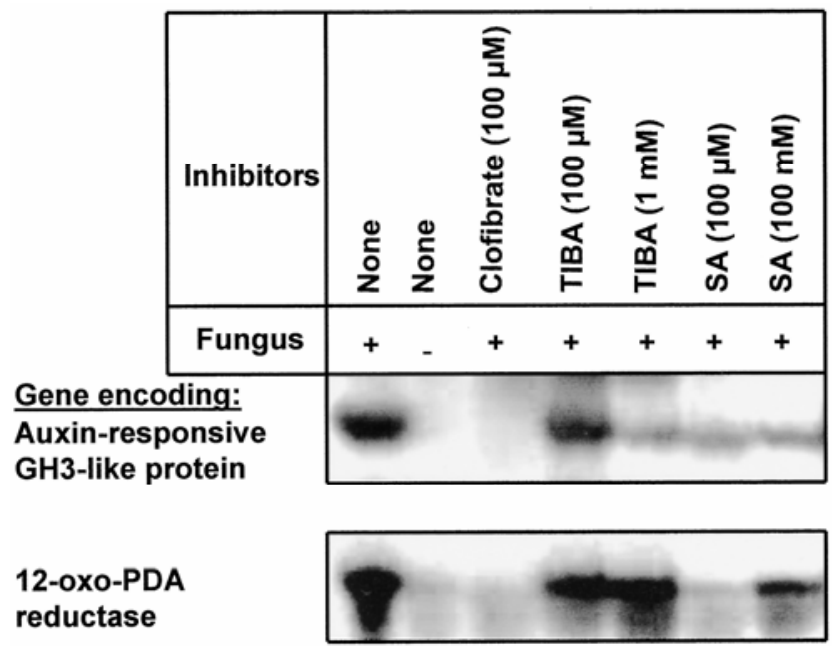

Fig. 7. Northern blot analysis of sweet orange flowers inoculated with Colletotrichum acutatum followed by treatment with 2-(4-chlorophenoxy)-2methyl-propionic acid (clofibrate), 2,3,5-triiodobenzolic acid (TIBA), and salicylic acid (SA). Transcripts of auxin-responsive GH-3 like protein and 12-oxo-phytodienoic acid reductase were used.

Table 2. Effect of hormone inhibitors on young fruit retention after inoculation with Colletotrichum acutatum on grapefruit (Citrus paradisi) and 'Valencia' sweet orange (C. sinensis) in 2003

\begin{tabular}{|c|c|c|c|}
\hline \multirow[b]{2}{*}{ Compounds, concentration ${ }^{b}$} & \multicolumn{2}{|c|}{ Fruit retention $^{a}$} & \multirow[b]{2}{*}{ Comments } \\
\hline & Number in grapefruit $(\%)$ & Number in sweet orange (\%) & \\
\hline \multicolumn{4}{|l|}{ TIBA } \\
\hline $1 \mu \mathrm{M}$ & $14 / 199(9.4)$ & $11 / 136(8.1)$ & $\ldots$ \\
\hline $100 \mu \mathrm{M}$ & $7 / 120(5.8)$ & 20/137 (14.6) & $\ldots$ \\
\hline $1 \mathrm{mM}$ & $1 / 278(0.4)$ & $0 / 145(0)$ & Twig necrosis, defoliation \\
\hline \multicolumn{4}{|l|}{ Clofibrate } \\
\hline $1 \mu \mathrm{M}$ & $8 / 219(3.7)$ & $11 / 116(9.5)$ & \\
\hline $100 \mu \mathrm{M}$ & $0 / 55(0)$ & 20/199 (10.1) & Defoliation \\
\hline $1 \mathrm{mM}$ & $4 / 118(3.4)$ & $10 / 123(8.1)$ & Defoliation \\
\hline \multicolumn{4}{|l|}{ SA } \\
\hline $1 \mu \mathrm{M}$ & $6 / 117(5.1)$ & $5 / 85(5.9)$ & $\ldots$ \\
\hline $100 \mu \mathrm{M}$ & $3 / 113(2.7)$ & $5 / 105(3.4)$ & $\ldots$ \\
\hline $1 \mathrm{mM}$ & $0 / 155(0)$ & $10 / 123(8.1)$ & $\ldots$ \\
\hline \multicolumn{4}{|l|}{ Benlate } \\
\hline $1.9 \mathrm{~g} \mathrm{liter}^{-1}$ & $0 / 110(0)$ & $9 / 137(6.6)$ & $\ldots$ \\
\hline $\mathrm{H}_{2} \mathrm{O}$ & $3 / 92(3.3)$ & $1 / 78(1.3)$ & $\ldots$ \\
\hline
\end{tabular}


The plant hormone ethylene has been demonstrated to play a critical role in abscission, likely by accelerating organ separation at the abscission zone (Giovannoni 2001; Goren 1993). Ethylene production is regulated through regulation expression of ACC synthase and ACC oxidase (Johnson and Ecker 1998). Both ACC synthase and ACC oxidase enzymes are encoded by multiple families, but are differentially expressed in response to various stimuli, including pathogen infection and senescence (Bleecker and Kende 2000). In this study, infection of citrus flower petals by $C$. acutatum elevated the level of ethylene compared with that of the water control, suggesting a role for ethylene in young fruit drop caused by $C$. acutatum. Significant increases of ethylene were detected during the infection process, and accumulation of ACC oxidase and ACC synthase gene transcripts, indicating de novo biosynthesis of ethylene in response to fungal invasion. These results indicate that ethylene may have an important role in young fruit drop caused by $C$. acutatum. An increase of ethylene after fungal infection also may implicate a resistant reaction because ethylene acts alone or through a synergistic interaction with JA to promote the expression of plant defense genes (Chang and Shockey 1999; Dong 1998).

Although applying exogenous ABA may promote fruit abscission in citrus (Goren 1993), the role of ABA in young fruit drop remains unclear. In healthy flowers, the amounts of $\mathrm{ABA}$ increased in petals during maturation, but decreased in pistils. Infection of citrus flowers by $C$. acutatum did not significantly alter the ABA concentrations. The transcript levels of the gene involved in ABA biosynthesis were also not significantly different. The data indicated that ABA plays little or no role in young fruit drop caused by $C$. acutatum.

JA, methyl-JA, and related cyclopentanones are important plant signal molecules suggested to be involved in a variety of critical functions, including induction of plant defense against pathogens and insects, protection from ozone damage, reproductive development, and fruit ripening (Creelman and Mullet 1995, 1997; Staswick et al. 2002). The compound 12-oxo-PDA is the JA biosynthetic precursor and also may serve as an effective signal (Stintzi et al. 2001). Although little is known about the role of JA and its derivatives in young fruit abscission, JA has been shown to induce senescence and leaf abscission in bryony (Sembdner and Parthier 1993). The senescence response includes a loss of chlorophyll and degradation of chloroplast ribulose bisphosphate carboxylase (Weiler et al. 1993). JA also has been shown to trigger fruit ripening in tomato, likely by inducing ethylene biosynthesis (Creelman and Mullet 1995, 1997; O'Donnell et al. 1996). Field experiments have shown that application of exogenous methyl-JA can induce mature fruit abscission in citrus (Hartmond et al. 2000). In this study, we observed a rapid induction of both 12-oxo-PDA and cis-JA in citrus flower petals after infection by $C$. acutatum. Moreover, application of clofibrate or SA, but not TIBA, decreased the accumulation of the transcript of the gene encoding 12-oxo-PDA reductase. These results suggest that JA signaling may play a role in citrus young fruit drop caused by $C$. acutatum. JA has been shown to be a signal for stress-induced gene expression (Dong 1998; Li et al. 2002; van Wees et al. 2000; Vijayan et al. 1998); therefore, the rapid accumulation of JA and 12-oxo-PDA in citrus flower petals also may lead to downstream defensive reactions that contribute to the host-pathogen response.

The levels of JA and SA are known to increase upon infection by pathogens (Creelman and Mullet 1995; Dong 1998). As with JA, the plant signaling molecule SA plays an important role in pathways involved in induced disease resistance by regulating many pathogenesis-related (PR) genes (Reymond and Farmer 1998). The JA-dependent and SA-dependent signaling pathways also are tightly interconnected, and cross-talk between these pathways has been shown to be important in regulation of defense gene expression (Reymond and Farmer 1998). SA is an inhibitor of JA biosynthesis and action (Doares et al. 1995; Peña-Cortés et al. 1993). In this study, SA levels were induced in citrus flower petals but not in pistils after $C$. acutatum infection, suggesting that the accumulation of SA is in response to fungal attack. The role of SA in fruit abscission is unknown. Field tests showed that application of SA up to 10 $\mathrm{mM}$ has no effect on mature fruit and leaf abscission in citrus (J. K. Burns, unpublished). However, SA has been shown to play a role in regulating gene expression during leaf senescence in Arabidopsis spp. (Morris et al. 2000). Alternatively, SA might be involved indirectly in young fruit drop by interacting with JA and other growth regulators. Application of external SA significantly decreased the transcript of gene encoding 12oxo-PDA reductase, but increased young fruit retention, indicating that SA influenced JA-related signaling.

In conclusion, plant defense in response to microbial attack usually is regulated through a complex network of signaling pathways that are involved in SA, JA, and ethylene. In this study, we have demonstrated that the response of citrus flower petals to $C$. acutatum is associated with hormonal imbalance and, likely, also a limited defense response that consequently leads to young fruit abscission. We have shown that infection of citrus flower petals by $C$. acutatum triggers significant accumulation of IAA, ethylene, JA, and 12-oxo-PDA, supporting the role of these growth regulators in the development of symptoms and disease progression.

\section{MATERIALS AND METHODS}

Biological materials.

C. acutatum infects flower petals of all citrus cultivars. Calamondin (Citrus madurensis Lour), a species that produces off-season flowers, was used in all experiments unless otherwise indicated. Grapefruit (C. paradisi Macf.) and 'Valencia' sweet orange $(C$. sinensis Osbeck) trees that produce uniform inflorescences in spring were used to evaluate the effects of hormone inhibitors for young fruit retention after fungal infection. The plants were maintained in 10-gallon pots in a screenhouse (Citrus Research and Education Center, University of Florida-Lake Alfred). Trees usually flowered in February and March in Florida. To produce off-season flowers, plants were kept repeatedly under drought conditions for five to seven days, and water was applied from the shallow tray after leaves were slightly wilted. Isolates of $C$. acutatum that cause postbloom fruit drop of citrus were isolated from infected flower petals of sweet orange in Florida Chung et al. 2002a, and fungal inoculation was performed as described previously (Li et al. 2003). The infected petals developed water-soaked, orange-brown lesions after three to five days. The infected flowers, including fruitlets, were harvested for hormone and RNA purification.

To evaluate the efficacy of hormone inhibitors on young fruit retention, grapefruit and sweet orange tree inflorescences in spring were inoculated with a PFD isolate of Colletotrichum acutatum. Benlate (Benomyl) was applied 1 day prior to inoculation. Hormone inhibitors then were applied seven days postinoculation, and young fruit retained on trees were evaluated after 30 days. Each treatment had at least six different branches containing over 100 fruit. Results are presented as the number of young fruit after chemical application over the number of fruit before inoculation.

Chemicals TIBA, clofibrate, JA, and SA were purchased from Sigma-Aldrich (St. Louis). The compounds were dissolved in water, and the $\mathrm{pH}$ of solutions was adjusted to 6.5 to 7.5 before applying to young fruit using a SpraTool sprayer (Crown, Woodstock, IL, U.S.A.). 
Purification and quantification of phytohormones.

The amounts of ethylene, IAA, and ABA were measured in calamondin flowers with and without fungal inoculation. Ethylene was collected daily from an individual flower sealed in a $50-\mathrm{ml}$ syringe with plastic stoppers. Ethylene production was determined using a gas chromatograph (Hewlett-Packard, Avondale, PA, U.S.A.) as described by Hartmond and associates (2000), and its concentration was expressed in nanoliters per flower. IAA and ABA were extracted simultaneously at 2-day intervals from flower petals or pistils with $80 \%$ methanol containing butylated hydroxytoluene (BHT) at $40 \mathrm{mg} / \mathrm{ml}$ as described by Yuan and associates (2001) and further separated by high-performance liquid chromatography under conditions used by Miller and associates (1987). The amounts of IAA and ABA were quantified with enzyme-linked immunosorbent assay using monoclonal antibodies in Phytodetek-ABA and -IAA kits (Agdia Inc., Elkhart, IN, U.S.A.) according to the manufacturer's recommendation, and their concentrations were expressed in picomoles per gram of fresh weight. All treatments with three or five replicates were performed at least three times.

Purification and quantification of JA, 12-Oxo-PDA, and SA.

JA, 12-oxo-PDA, and SA were purified as described by Schmelz and associates (2003) and Engelberth and associates (2003) with modifications. Briefly, $200 \mathrm{mg}$ of citrus petals or pistils was frozen in liquid nitrogen, ground to a fine powder, and dissolved in $50 \mathrm{mM}$ citric acid buffer (in $\mathrm{H}_{2} \mathrm{O}$ /acetone; $30 / 70$ [vol/vol]). The acetone was evaporated under a constant air stream. The remaining solution was extracted twice with diethyl ether. Ether phases were combined and dried under a constant air stream. Plant signaling compounds were methylated by dissolving in $\mathrm{HCl}(37 \%) /$ methanol $(1 / 2$ [vol/vol]) at $70^{\circ} \mathrm{C}$ for $45 \mathrm{~min}$ in a 4-ml screw-cap vial, then neutralized using $1 \mathrm{M}$ citric acid. After heating at $80^{\circ} \mathrm{C}$, volatilized compounds were trapped in a Super Q filter containing $30 \mathrm{mg}$ of absorbent and a Teflon vent tubing, and the compounds were eluted with $150 \mu \mathrm{l}$ of dichloromethane as described by Engelberth and associates (2003). The volatilized plant signaling compounds were analyzed using a model HP 6890 gas chromatograph equipped with a split/splitless injector and connected to an HP5973 mass spectrometer (Hewlett-Packard, Palo Alto, CA, U.S.A.), and operated in chemical ionization mode using isobutene as an ionization gas. Compounds then were separated on an HP$1 \mathrm{MS}$ column $\left(30 \mathrm{~m}\right.$ by $0.25 \mathrm{~mm}$ by $0.25 \mathrm{~m}$ ) at $40^{\circ} \mathrm{C}$ for $1 \mathrm{~min}$ after injection and temperature programmed at $15^{\circ} \mathrm{C} / \mathrm{min}$ to $250^{\circ} \mathrm{C}$ for $10 \mathrm{~min}$ using helium as a gas carrier. All compounds were identified by comparison of their retention time and fragmentation with pure commercially available standards, and further quantified by correlating the peak area of the compounds with the corresponding internal standard.

\section{DNA manipulation.}

In separate studies, several hundred cDNA fragments that were differentially expressed after application of the abscission agent (5-chloro-3-methyl-4-nitro-1H-pyrazole at $200 \mathrm{mg} / \mathrm{liter}$ ) were identified by subtractive hybridization from cDNA libraries prepared from fruit abscission zones of 'Valencia' sweet orange (Burns 2002). The cDNA fragments were end-filled with adaptors (Clontech, Palo Alto, CA, U.S.A.), then amplified by polymerase chain reaction (PCR) using two linker primers (5'-tcgagcggecgccegggcaggt-3' and 5'-agcgtggtcgcgg ccgaggt- $\left.3^{\prime}\right)$ and directly cloned into pGEM-T easy vector (Promega Corp., Madison, WI, U.S.A.). The cDNA clones related to regulation and biosynthesis of hormones and growth regulators were selected to examine differential gene expressions after $C$. acutatum infection as previously de- scribed (Li et al. 2003). A DNA fragment (Table 1; clone \#0315) containing partial 9-cis-epoxycarotenoid dioxygenase gene was obtained using PCR from the total DNA of 'Valencia' sweet orange with two degenerate primers (5'-ttygayggng ayggnatg- $3^{\prime}$ and $5^{\prime}$-gcrttccanagraarcaraarcar- $\left.3^{\prime}\right)$ derived from conserved amino acid sequences of 9-cis-epoxycarotenoid dioxygenase of various plants (Qin and Zeevaart 1999). A DNA fragment (Table 1; clone \#0312) containing partial ACC synthase gene was amplified using two gene-specific primers, 5'-tgaacactgtggcagcataa-3' and 5'-ccgaccgtattgtatgagtg-3' (Wong et al. 1999). PCR fragments were cloned into pGEM-T vector for sequencing analysis. Plasmid DNA was propagated in Escherichia coli $\mathrm{DH} 5 \alpha$ competent cells (Invitrogen Life Technologies, Carlsbad, CA, U.S.A.), and was isolated with a Wizard DNA purification kit (Promega Corp.). The DNA probes used for Northern blot hybridization were labeled by PCR incorporation of digoxigenin-11-dUTP (Roche Applied Science, Indianapolis, IN, U.S.A.) using the linker primers or gene-specific primers. The conditions used for PCR amplification and labeling were as previously described (Chung et al. 1996). DNA sequencing was performed at the Integrated Biotechnology Lab, University of Georgia (Athens, U.S.A.). Database searches and comparisons were conducted using BLAST network service at the National Center of Biotechnology Information (Altschul et al. 1997).

\section{RNA isolation and Northern blot analysis.}

Citrus total RNA was extracted using a RNA Isolator kit (Invitrogen) according to the manufacturer's recommendation. Denaturing electrophoresis of RNA in formaldehyde-containing agarose gels was as described by Chung and associates (2003a), followed by transfer onto positively charged nylon membranes (Osmonics, Westborough, MA, U.S.A.). Hybridization was conducted in PerfectHyb solution (Sigma-Aldrich) at $65^{\circ} \mathrm{C}$ for $5 \mathrm{~h}$. The conditions for post-hybridization wash and probe detection were performed as described by $\mathrm{Li}$ and associates (2003).

\section{ACKNOWLEDGMENTS}

This research was supported by the Florida Agricultural Experiment Station and grants from the Florida Citrus Production Research Advisory Council (FCPRAC) \#012-04P and \#033-03P (to K. R. Chung), and approved for publication as Journal Series No. R-10206. We thank J. W. Grosser and J. H. Graham for helpful comments, J. Engelberth for JA and SA analyses, and L. G. Albrigo for flower induction.

\section{LITERATURE CITED}

Altschul, S. F., Madden, T. L., Schaffer, A. A., Zhang, J., Zhang, Z., Miller, W., and Lipman, D. J. 1997. Gapped BLAST and PSI-BLAST: A new generation of protein database search programs. Nucleic Acids Res. 25:3389-3402.

Agostini, J. P., Timmer, L. W., and Mitchell, D. J. 1992. Morphological and pathological characteristics of strains of Colletotrichum gloeosporioides from citrus. Phytopathology 82:1377-1382.

Anderson, J. V., and Davis, D. G. 2004. Abiotic stress alters transcript profiles and activity of glutathion S-transferase, glutathion peroxidase, and glutathion reductase in Euphorbia esula. Physiol. Plant. 120:421433.

Bangerth, F. 1997. Can regulatory mechanism in fruit growth and development be elucidated through the study of endogenous hormone concentrations? Acta Hortic. 463:77-87.

Bangerth, F. 2000. Abscission and thinning of young fruit and their regulation by plant hormones and bioregulators. Plant Growth Regul. 31:43-59.

Bartel, B., and Fink, G. R. 1995. ILR1, an amidohydrolase that release active indole-3-acetic acid from conjugates. Science 268:1745-1748.

Bleecker, A. B., and Kende, H. 2000. Ethylene: A gaseous signal molecule in plants. Annu. Rev. Cell Dev. Biol. 16:1-18.

Bonghi, C., Tonutti, P., and Ramina, A. 2000. Biochemical and molecular aspects of fruitlet abscission. Plant Growth Regul. 31:35-42. 
Brown, A. E., Sreenivasaprasad, S., and Timmer, L. W. 1996. Molecular characterization of slow-growing orange and key lime anthracnose strains of Colletotrichum from citrus as C. acutatum. Phytopathology 86:523527

Brown, G. E. 1992. Factors affecting the occurrence of anthracnose on Florida citrus fruit. Proc. Int. Soc. Citricult. 3:1044-1048.

Burns, J. K. 2002. Using molecular biology tools to identify abscission materials for citrus. Hort Science 37:15-20.

Chang, C., and Shockey J. A. 1999. The ethylene-response pathway: Signal perception to gene regulation. Curr. Opin. Plant Biol. 2:352-358.

Chung, K.-R., Leuchtmann, A., and Schardl, C. L. 1996. Inheritance of mitochondrial DNA and plasmids in the ascomycetous fungus, Epichlo $\ddot{e}$ typhina. Genetics 142:259-265.

Chung, K.-R., Shilts, T., Li, W., and Timmer, L. W. 2002a. Engineering a genetic transformation system for Colletotrichum acutatum, the causal fungus of lime anthracnose and postbloom fruit drop of citrus. FEMS (Fed. Eur. Microbiol. Soc.) Microbiol. Lett. 213:33-39.

Chung, K.-R., Yuan, R., Burns, J. K., and Timmer, L. W. 2002b. Involvement of hormones in symptomatology of postbloom fruit drop (PFD) of citrus caused by Colletotrichum acutatum. (Abstr.) Phytopathology 92:S15.

Chung, K.-R., Daub, M. E., and Ehrenshaft, M. 2003a. Expression of cercosporin toxin resistance gene $(C R G 1)$ as a dicistronic unit with a functionally unrelated gene in the phytopathogenic fungus Cercospora nicotianae. Curr. Genet. 43:415-424.

Chung, K.-R., Shilts, T., Ertürk, Ü., Timmer, L. W., and Ueng, P. P. 2003b. Indole derivatives produced by the fungus Colletotrichum acutatum causing lime anthracnose and postbloom fruit drop of citrus. FEMS (Fed. Eur. Microbiol. Soc.) Microbiol. Lett. 226:23-30.

Creelman, R. A., and Mullet, J. E. 1995. Jasmonic acid distribution and action in plants: Regulation during development and response to biotic and abiotic stress. Proc. Natl. Acad. Sci. U.S.A. 92:4114-4119.

Creelman, R. A., and Mullet, J. E. 1997. Biosynthesis and action of jasmonates in plants. Annu. Rev. Plant Physiol. Plant Mol. Biol. 48:355-381.

Doares, S. H., Narvaez-Vasquez, J., Conconi, A., and Ryan, C. A. 1995. Salicylic acid inhibits synthesis of proteinase inhibitors in tomato leaves induced by systemin and jasmonic acid. Plant Physiol. 108:1741-1746.

Dong, X. 1998. SA, JA, ethylene, and disease resistance in plants. Curr. Opin. Plant Biol. 1:316-323.

Dupree, P. 1996. Plant embryogenesis: Cell division forms a pattern. Curr Biol. 6:683-685.

Engelberth, J., Schmelz, E. A., Alborn, H. T., Cardoza, Y. J., Huang, J., and Tumlinson, J. H. 2003. Simultaneous quantification of jasmonic acid and salicylic acid in plants by vapor-phase extraction and gas chromatography-chemical ionization-mass spectrometry. Anal. Biochem. 312:242-250

Giovannoni, J. 2001. Molecular biology of fruit maturation and ripening. Annu. Rev. Plant Physiol. Plant Mol. Biol. 52:725-749.

Gómez-Cadenas, A., Mehouachi, J., Tadeo, F. R., Primo-Millo, E., and Talon, M. 2000. Hormonal regulation of fruitlet abscission induced by carbohydrate shortage in citrus. Planta 210:636-643.

Goren, G. 1993. Anatomical, physiological, and hormonal aspects of abscission in citrus. Hortic. Rev. 15:33-46.

Hartmond, U., Yuan, R., Burns, J. K., Grant, A., and Kender, W. J. 2000. Citrus fruit abscission induced by methyl-jasmonate. J. Am. Soc. Hortic. Sci. 125:547-552.

Johnson, P. R., and Ecker, J. R. 1998. The ethylene gas signal transduction pathway: A molecular perspective. Annu. Rev. Genet. 32:227-254.

Kaneta, T., Kakimoto, T., and Shibaoka, H. 1997. Gibberellin A3 causes a decrease in the accumulation of mRNA for ACC oxidase and in the activity of the enzyme in azuki bean (Vigna angularis) epicotyls. Plant Cell Physiol. 38:1135-1141.

Li, L., Li, C., Lee, G. I., and Howe, G. A. 2002. Distinct roles for jasmonate synthase and action in systemic wound response of tomato. Proc. Natl. Acad. Sci. U.S.A. 99:6416-6421.

Li, W., Yuan, R., Burns, J. K., Timmer, L. W., and Chung, K.-R. 2003. Genes for hormone biosynthesis and regulation are highly expressed in citrus flowers infected with the fungus Colletotrichum acutatum, causal agent of postbloom fruit drop. J. Am. Soc. Hortic. Sci. 128:578-583.

Liyanage, H. D., Koller, W., McMillan, R. T., Jr., and Kistler, H. C. 1993. Variation in cutinase from two populations of Colletotrichum gloeosporioides from citrus. Phytopathology 83:113-116.

Liyanage, H. D., McMillan, R. T., Jr., and Kistler, H. C. 1992. Two genetically distinct populations of Colletotrichum gloeosporioides in Florida. Phytopathology 82:1371-1376.

Miller, A. N., Walsh, C. S., and Cohen, J. D. 1987. Measurement of indole-3acetic acid in peach fruits (Prunus persica L. Batsch cv. Redhaven) during development. Plant Physiol. 84:491-494.

Morris, K., Mackerness, S. A. H., Page, T., John, C. F., Murphy, A. M., Carr,
J. P., and Buchanan-Wollaston, V. 2000. Salicylic acid has a role in regulating gene expression during leaf senescence. Plant J. 23:677-685.

Nakamura, Y., Sato, S., Asamizu, E., Kaneko, T., Kotani, H., Miyajima, N., and Tabata, S. 1998. Structural analysis of Arabidopsis thaliana chromosome 5. VII. Sequence features of the regions of 1,010,767 bp covered by sixteen physically assigned P1 and TAC clones. DNA Res. 5:297-308

O’Donnell, P. J., Calvert, C., Atzorn, R., Wasternack, C., Leyser, H. M. O. and Bowles, D. 1996. Ethylene as a signal mediating the wound response of tomato plants. Science 274:1914-1917.

Peña-Cortés, H., Albrecht, T., Prat, S., Weiler, E. W., and Willmitzer, L. 1993. Aspirin prevents wound-induced gene expression in tomato leaves by blocking jasmonic acid biosynthesis. Planta 191:123-128.

Qin, X., and Zeevaart, J. A. D. 1999. The 9-cis-epoxycarotenoid cleavage reaction is the key regulatory step of abscisic acid biosynthesis in waterstressed bean. Proc. Natl. Acad. Sci. U.S.A. 96:15354-15361.

Reymond, P., and Farmer, E. E. 1998. Jasmonate and salicylate as global signals for defense gene expression. Curr. Opin. Plant Biol. 1:404-411.

Romo, S., Labrador, E., and Dopico, B. 2001. Water stress-regulated gene expression in Cicer arietinum seedlings and plants. Plant Physiol. Biochem. 39:1017-1026.

Roux, C., Bilang, J., Theunissen, B. H., and Perrot-Rechenmann, C. 1998. Identification of new early auxin markers in tobacco by mRNA differential display. Plant Mol. Biol. 37:385-389.

Sanders, P. M., Lee, P. Y., Biesgen, C., Boone, J. D., Beals, T. P., Weiler, E. W., and Goldberg, R. B. 2000. The Arabidopsis DELAYED DEHISCENCE1 gene encodes an enzyme in the jasmonic acid synthesis pathway. Plant Cell 12:1041-1061.

Schmelz, E. A., Engelberth, J., Alborn, H. T., O’Donnell, P., Sammons, M., Toshima, H., and Tumlinson, J. H. 2003. Simultaneous analysis of phytohormones, phytotoxins, and volatile organic compounds in plants. Proc. Natl. Acad. Sci. U.S.A. 100:10552-10557.

Sembdner, G., and Parthier, B. 1993. The biochemistry and the physiological molecular actions of jasmonates. Annu. Rev. Plant Physiol. Plant Mol. Biol. 44:569-589.

Sosa-Morales, M. E., Guevara-Lara, F., Martínez-Juárez, V. M., and ParedesLópez, O. 1997. Production of indole-3-acetic acid by mutant strains of Ustilago maydis (maize smut/huitlacoche). Appl. Microbiol. Biotechnol. 48:726-729.

Staswick, P. E., Tiryaki, I., and Rowe, M. L. 2002. Jasmonate response locus JAR1 and several related Arabidopsis genes encode enzymes of the firefly luciferase superfamily that show activity on jasmonic, salicylic, and indole-3-acetic acids in an assay for adenlyation. Plant Cell 14:1405-1415

Stintzi, A., Weber, H., Reymond, P., Browse, J., and Farmer, E. E. 2001 Plant defense in the absence of jasmonic acid: The role of cyclopentanones. Proc. Natl. Acad. Sci. U.S.A. 98:12837-12842.

Talon, M., Tadeo, F. R., Ben-Cheikh, W., Gómez-Cadenas, A., Mehouachi, J., Perez-Botella, J., and Primo-Millo, E. 1997. Hormonal regulation of fruit set and abscission in citrus: Classical concepts and new evidence. Acta Hortic. 463:209-217.

Timmer, L. W., Agostini, J. P., Zitko, S. E., and Zulfiqar, M. 1994. Postbloom fruit drop, an increasingly prevalent disease of citrus in the Americas. Plant Dis. 78:329-334.

Timmer, L. W., Brown, G. E., and Zitko, S. E. 1998. The role of Colletotrichum spp. in postharvest anthracnose of citrus and survival of C. acutatum of fruit. Plant Dis. 82:415-418.

Tsurumi, S., and Ohwaki, Y. 1978. Transport of ${ }^{14} \mathrm{C}$-labeled indoleacetic acid in Vicia root segments. Plant Cell Physiol. 39:1111-1118.

van Wees, S. C. M., de Swart, E. A. M., van Pelt, J. A., van Loon, L. C., and Pieterse, C. M. J. 2000. Enhancement of induced disease resistance by simultaneous activation of salicylate- and jasmonate-dependent defense pathways in Arabidopsis thaliana. Proc. Natl. Acad. Sci. U.S.A. 97:8711-8716.

Vijayan, P., Shockey, J., Levesque, C. A., Cook, R. J., and Browse, J. 1998. A role for jasmonate in pathogen defense of Arabidopsis. Proc. Natl. Acad. Sci. U.S.A. 95:7209-7214.

Weiler, E. W., Albrecht, T., Groth, B., Xia, Z.-Q., Luxem, M., Li, H., Andert, L., and Spengler, P. 1993. Evidence for the involvement of jasmonates and their octadecanoid precursors in the tendril coiling response of Bryonia doica. Phytochemistry 32:591-600.

Wong, W. S., Ning, W., Xu, P. L., Kung, S. D., Yang, S. F., and Li, N. 1999. Identification of two chilling-regulated 1-aminocyclopropane-1carboxylate synthase genes from citrus (Citrus sinensis Osbeck) fruit Plant Mol. Biol. 41:587-600.

Yuan, R., Hartmond, U., and Kender, J. W. 2001. Physiological factors affecting response of mature 'Valencia' orange fruit to CMN-pyrazole. II. Endogenous concentrations of indole-3-acetic acid, abscisic acid, and ethylene. J. Am. Soc. Hortic. Sci. 126:420-426. 